\title{
The Impact of the Presence of Intellectual Disabilities on Sensory Processing and Behavioral Outcomes Among Individuals with Autism Spectrum Disorders: a Systematic Review
}

\author{
M. F. Werkman ${ }^{1}$. J. A. Landsman ${ }^{2}$ - A. S. Fokkens ${ }^{2} \cdot$ Y. M. Dijkxhoorn ${ }^{3} \cdot$ I. A. van Berckelaer-Onnes ${ }^{4} \cdot$ S. Begeer ${ }^{5}$. \\ S. A. Reijneveld ${ }^{1}$
}

Received: 11 December 2020 / Accepted: 3 January 2022

(c) The Author(s) 2022

\begin{abstract}
Background Autism spectrum disorder and intellectual disability (ID) are linked to atypical sensory processing, but consensus lacks on the impact of their co-occurrence. We studied the impact of the presence of ID in autistic individuals on (1) sensory processing and (2) the relation between sensory processing and behavioral outcomes.

Methods A systematic review was performed on English-language peer-reviewed studies.

Results Eleven papers were included. Papers based on overall and sensory subscales reported no impact of the presence of ID. Papers based on subtypes reported hyporesponsiveness and sensory seeking related to the presence of ID; hyporesponsiveness showed the poorest behavioral outcomes.

Conclusions Findings regarding the impact of the presence of ID are contradictory. More research regarding sensory subtypes is needed to investigate the needs of autistic individuals with ID.
\end{abstract}

Keyword Autism spectrum disorder; Intellectual disability; Sensory processing; Behavioral outcomes; Systematic review

Individuals with an autism spectrum disorder (ASD) or an intellectual disability (ID) show more atypical sensory processing than the general population (e.g., Engel-Yeger et al. 2011; Jussila et al. 2020). However, consensus is lacking regarding the impact of combined ASD and ID on sensory

\section{F. Werkman}

m.f.werkman@umcg.nl

1 Department of Health Sciences, University Medical Center Groningen, University of Groningen, P.O. Box 30.001, FA10, 9700 RB Groningen, the Netherlands

2 Department of Health Sciences, Applied Health Research, University Medical Center Groningen, University of Groningen, Groningen, the Netherlands

3 Faculty of Social and Behavioural Sciences, Clinical Child and Adolescent Studies, LUBEC, University of Leiden, Leiden, the Netherlands

4 Faculty of Social and Behavioural Sciences, Clinical Child and Adolescent Studies, University of Leiden, Leiden, the Netherlands

5 Department of Clinical, Neuro and Developmental Psychology, Vrije Universiteit Amsterdam, and Amsterdam Public Health Research Institute, Amsterdam, the Netherlands processing. Considering the disorders separately, within ASD the majority (45 to 95\%) of individuals experience atypical sensory processing (Ben-Sasson et al. 2019; Marco et al. 2011; Tomchek and Dunn, 2007). In the current ASD literature, sensory processing is categorized mainly under three distinctive patterns: (1) hyporesponsiveness, referring to a lack of, or muted response to, sensory stimuli (Baranek et al. 2006); (2) hyperresponsiveness, meaning showing exaggerated responses (Baranek et al. 2006); and (3) sensory seeking, meaning craving for sensory stimuli (Miller et al. 2007). This categorization is sometimes supplemented with (4) enhanced perception, referring to superior awareness to specific sensory stimuli and focus on specific elements of stimuli (Mottron et al. 2009). Hyper- or hyporeactivity to sensory input has recently been added to the fifth edition of the Diagnostic and Statistical Manual of Mental Disorders (DSM) as a diagnostic symptom of ASD (American Psychiatric Association (2013). With regard to ID, individuals with all levels of ID also seem to experience atypical sensory processing (Engel-Yeger et al. 2011), but to a lesser degree than individuals with only ASD (Rogers et al. 2003). Sensory processing problems in persons with ID may be caused by structural deviations in their central nervous system and 
related to their adaptive functioning (Engel-Yeger, et al. 2011). However, to date, no systematic review has been performed on studies of the impact of the presence of ID on sensory processing within the ASD population.

A substantial percentage (33\%) of ASD individuals has co-occurring ID, according to the latest estimates from the Centers for Disease Control and Prevention (Maenner et al. 2020). The co-occurrence of ASD and ID may lead to more and/or different sensory processing problems than ASD alone. However, evidence for this assumption is contradictory (Hazen et al. 2014). Some studies conclude that in lower functioning ASD individuals, more sensory processing domains are affected (e.g., Leekam et al. 2007), whereas another study reported a high prevalence of sensory processing problems in high-functioning ASD individuals (Hochhauser and Engel-Yeger, 2010). This contrast may be due to different hypotheses regarding the underlying mechanisms of each disorder (Kroon et al. 2013). The co-occurrence of ASD and ID may reinforce underlying mechanisms of each separate disorder, thereby amplifying atypical sensory processing.

Taxonomies of sensory processing are based on varying criteria: (1) variation in the severity of sensory processing problems; (2) variation in reactions to stimuli, such as differentiation into the sensory processing patterns, hyperresponsiveness, hyporesponsiveness, and sensory seeking; and/or (3) differentiation into the sensory modalities, e.g., the auditory, visual, vestibular, and proprioceptive senses (Ausderau et al. 2014; Lane et al. 2014; Uljarevic et al. 2016). These taxonomies are based on different assessments, like the Sensory Experiences Questionnaire (Baranek et al. 2006) and the Sensory Profile (Dunn, 1999). To date, no study has merged these different categorizations into one taxonomy, and consensus is lacking as to the distinct impact of the various categories on behavioral outcomes. A homogenous taxonomy should lead to subgroups of ASD individuals with similar sensory processing patterns. This could contribute to a better understanding of the etiological similarities of these patterns and to more uniform responses to interventions (Gottesman and Gould, 2003). Moreover, a differentiation in homogenous subgroups could contribute to our understanding of individual variability (e.g., Lane et al. 2014).

Consensus is also lacking regarding the extent to which sensory processing is associated with behavioral outcomes for individuals with a comorbidity of ASD and ID (Gonthier et al. 2016). In general, these individuals show more stereotyped and challenging behaviors and problems in their verbal and nonverbal communication as well as in their social and adaptive functioning (Matson et al. 2009). Moreover, the more severe the ID, the higher the rates of behavioral problems, and the greater the severity of these problems for individuals with combined ASD and ID (Matson and Shoemaker, 2009). However, evidence on the association between sensory processing and behavioral outcomes is lacking for these individuals with both ASD and ID.

For the total ASD population (with and without ID), or ASD individuals without ID, atypical sensory processing has been linked to several behavioral outcomes. In particular, specific sensory processing patterns have been linked to the internalizing problems anxiety (Mazurek et al. 2012) and depression (Bitsika et al. 2016) and to the externalizing problems stereotyped movements (Fetta et al. 2021) and restricted repetitive behaviors (Schulz and Stevenson, 2019). Sensory processing patterns have also been linked to social participation (Ismael et al. 2018), so far restricted to educational participation (e.g., Ashburner et al. 2008) and leisure participation (e.g., Hochhauser and Engel-Yeger, 2010). We thus have some knowledge about sensory processing and associated outcomes for the ASD population (Suarez, 2012), but little is known about these associations in individuals with both ASD and ID (Gonthier et al. 2016).

Therefore, we aimed to investigate (1) the impact of the presence of ID on sensory processing in individuals with ASD and (2) the impact of the presence of ID on the relation between sensory processing and behavioral outcomes in individuals with ASD.

\section{Methods}

\section{Search Strategy}

We performed this review following the 27 steps of the checklist of the Preferred Reporting Items for Systematic Reviews and Meta-Analyses (PRISMA) Group (Moher et al. 2009). The databases PubMed, PsycINFO, and Education Resources Information Center (ERIC) were searched. For each database, a specific search strategy was developed, using "sensory processing" and "autism" as core search terms. Appendix A shows the full search strategies for all databases. Appendix B provides the completed PRISMA Checklist.

\section{Inclusion and Exclusion Criteria and Data Extraction}

We selected papers using the following inclusion criteria: (1) English language; (2) peer-reviewed primary studies from 2000 to 2019; (3) reported association between sensory processing and at least one behavioral outcome; (4) individuals with ASD separately reported as a distinct research group; (5) individuals with an ID (i.e., developmental functioning $<70$; see definition of variables) reported as part of the ASD sample; and (6) a main focus on sensory processing in general. We thus excluded papers focused exclusively on one modality 
(e.g., auditory) or one pattern (e.g., hyporesponsiveness) and papers which described different modalities for one pattern (e.g., auditory hyperresponsiveness). Exclusion criteria were (1) intervention studies, (2) studies in which measurement tools were validated, (3) studies providing only theoretical overview of sensory processing, (4) neurophysiological studies, and (5) studies exclusively including clinical groups, e.g., individuals with attention deficit hyperactivity disorder or sensory processing disorder. For full-text screening, papers were included that investigated aim 1, the impact of the presence of ID on sensory processing in individuals with ASD, and/or aim 2, the impact of the presence of ID on the relation between sensory processing and behavioral outcomes in individuals with ASD - i.e., papers that assessed only aim 1, only aim 2, or both. Two researchers (MW and JL) independently screened papers for eligibility, based on title and abstract. In case of disagreement, a third researcher (AF) gave her opinion. During the full-text screening, we contacted authors if papers did not report the level of functioning (e.g., IQ values or adaptive functioning) of their sample. If the inclusion of individuals with ID within the ASD sample remained unclear or we received no response, papers were excluded. Full-text screening and data extraction were performed by MW and JL or MW and AF. For data extraction, a standardized form was used, subdivided into descriptive information of the study, impact of the presence of ID on sensory processing (aim 1), impact of the presence of ID on the association between sensory processing and behavioral outcomes (aim 2 ), and conclusions and implications of the study.

\section{Definition of Variables}

We defined sensory processing as the reception, modulation, integration, and organization of sensory stimuli and behavioral responses to sensory input (Miller and Lane, 2000).

We divided behavioral outcomes under externalizing behavior, defined as the expression of outward behavior affecting the external environment (Campbell et al. 2000; Eisenberg et al. 2001); internalizing behavior, e.g., depression and anxiety, that influence the internal psychological environment (Campbell et al. 2000; Eisenberg et al. 2001); and social participation, defined in terms of functioning in five domains: school, work, independent living, friends, and community participation.

ID was defined as level of either adaptive or intelligence functioning or both. For inclusion in our review, the level of functioning had to be below 70 for the group of individuals with both ASD and ID on a standardized measurement scale (100 is average). For individuals with ASD, with and without ID (mixed group), the score should fall within a range from below to above 70 , or values below and above 70 , within one standard deviation. Studies were included when ID was a main or confounding variable in the statistical analyses of associations as well as when the sample was described based on ID.

\section{Quality Assessment}

To assess the quality of the included papers, we used the Quality in Prognosis Studies Instrument (Hayden et al. 2013). This instrument assesses six potential domains regarding risk of bias: (1) study participation, (2) study attrition, (3) prognostic factor measurement, (4) outcome measurement, (5) study confounding, and (6) statistical analysis and reporting. Pairs of researchers (MW and $\mathrm{JL}$ or MW and AF) performed a quality assessment of each included paper. Discrepancies between judgments were discussed and resolved. The six domain scores were assessed based on three to seven underlying questions. For the third domain, "prognostic factor measurement," the variable sensory processing was evaluated, and for the fourth domain, "outcome measurement," the variable behavioral outcome was assessed. As not all questions were applicable to the included papers, we decided in those cases to give an overall judgement of the domain (low, moderate, or high bias). If two or more domains got a score of "high," the overall bias of the research in this paper was also rated as high.

\section{Data Synthesis}

First, a flow chart describing the full process of selecting papers was presented. Second, each included study was described. Third, findings regarding the impact of the presence of ID on sensory processing, and the impact of the presence of ID on the relation of sensory processing with behavioral outcomes, were synthesized. We categorized studies as reporting or not reporting an impact of the presence of ID. Studies were grouped for syntheses under two types: (1) studies that included individuals with both ASD and ID and (2) studies that compared two separate groups of individuals with ASD: those with and those without ID. Finally, the quality assessment of the included papers was presented.

\section{Results}

\section{Study Selection}

For title/abstract screening, 933 papers were identified, 74 of which met the criteria and were included for full-text review for eligibility. Eleven papers made 
a differentiation in ID within the ASD population and were therefore included. The full selection process is presented in Fig. 1. Examples of reasons for exclusion were an ID sample (e.g., Joosten and Bundy, 2010), a lack of behavioral outcomes (e.g., Ben-Sasson et al. 2007), role of ID not researched (e.g., McCormick et al. 2016), ASD without ID (e.g., Hochhauser and Engel-Yeger, 2010), or exclusive focus on only one response pattern (hyporesponsiveness, e.g., Baranek et al. 2013).

\section{Characteristics of the Included Studies}

Six of the 11 included studies were cross-sectional studies. Nine of the 11 studies included children, with eight studies including a maximum age of 14 years in their sample, and one a mean age of eight and a half (with no maximum reported) (Liss et al. 2006). The other two studies included both children and adolescents with a maximum age of 20 years (Gabriels et al. 2008) and adults with an age range of 19-59 years (Gonthier et al. 2016). For both sensory processing and behavioral outcomes, only proxy measures were used. The most frequently used measurement-instrument for sensory processing, was the Short Sensory Profile, and for behavioral outcomes the Vineland Adaptive Behavior Scale, both proxy-reported measures. The methods for assessing ID were more varied, including care center registrations (Gonthier et al. 2016), different measurement tools for intelligence or adaptive behavior, and several general development assessment tools. Studies also differed in the type of analysis used to investigate the impact of the presence of ID, for instance, performing correlation analyses, cluster analyses, and linear regression analyses or controlling for IQ. One study included only individuals with a comorbidity of ASD and ID (Gonthier et al. 2016); 10 studies included the mixed ASD group, i.e., ASD individuals with and without ID. All 11 studies used a study sample of $n>20$ (range: $N=26$ to $N=960$ ). Included ID levels varied from only individuals with a profound to severe ID (Gonthier et al. 2016) to a broad IQ range of 19 to 136 (Green et al. 2016). Table 1 presents the characteristics of each individual study, including the
Fig. 1 PRISMA flow diagram of included papers (Moher et al., 2009)

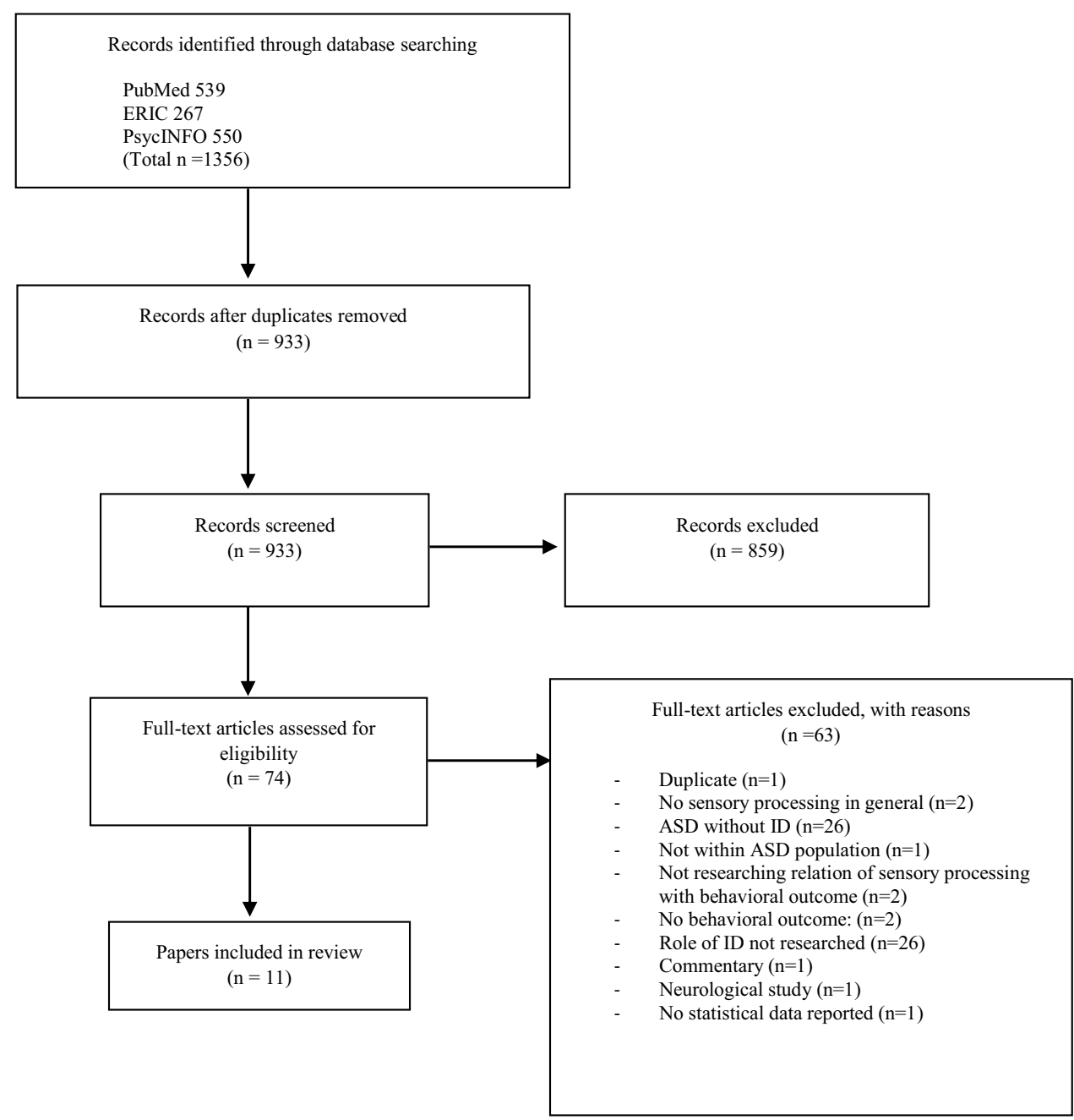




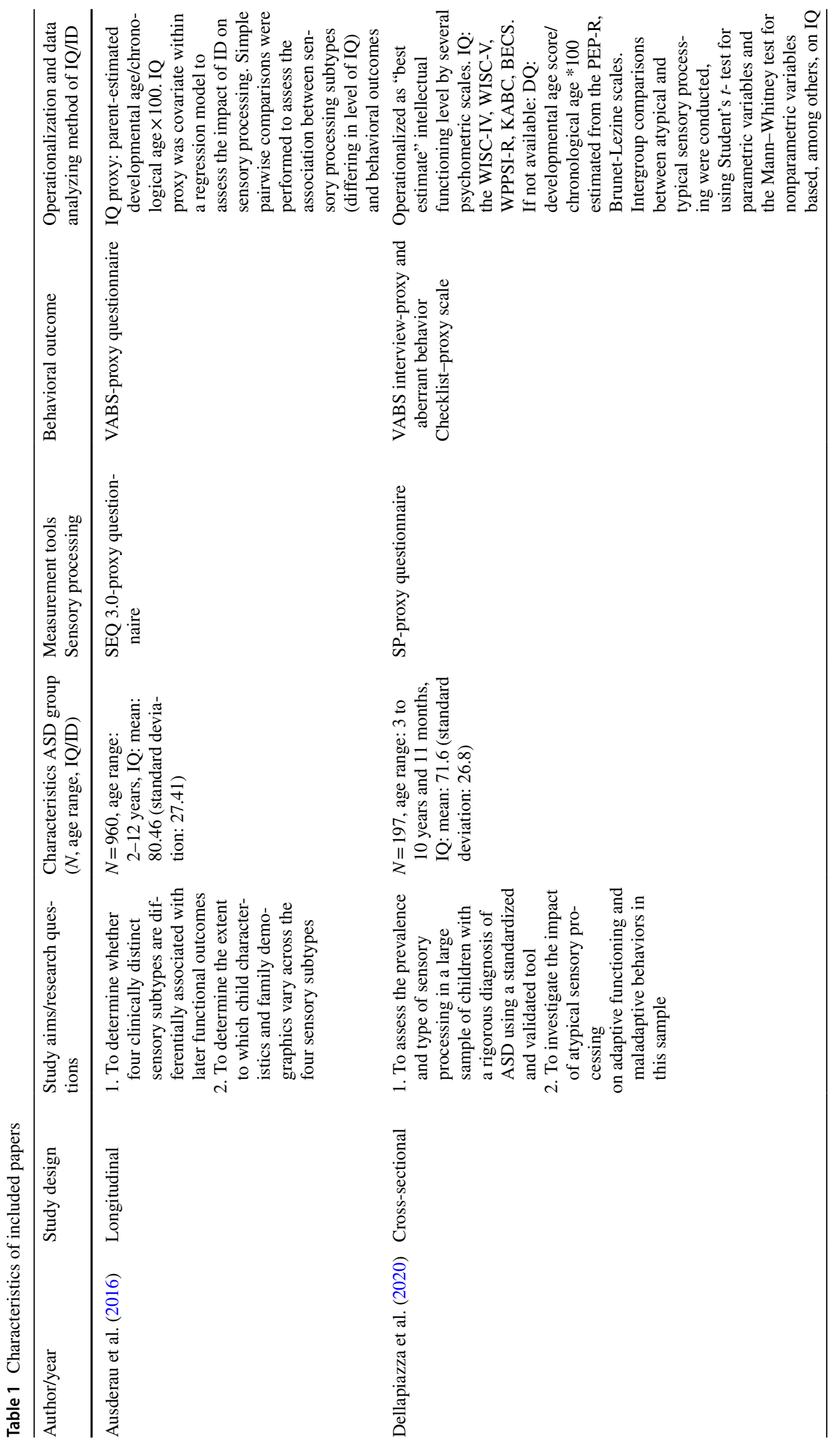




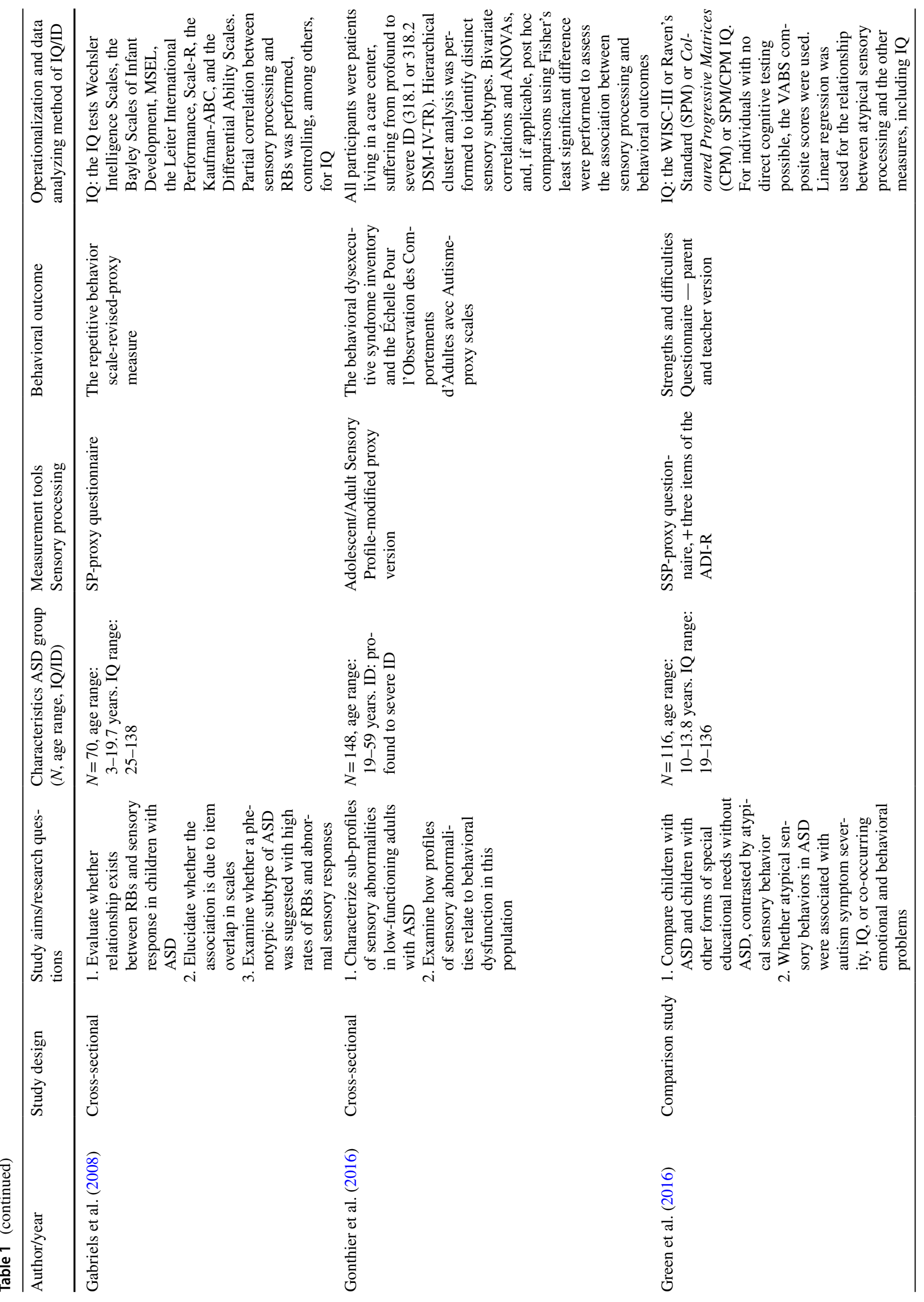




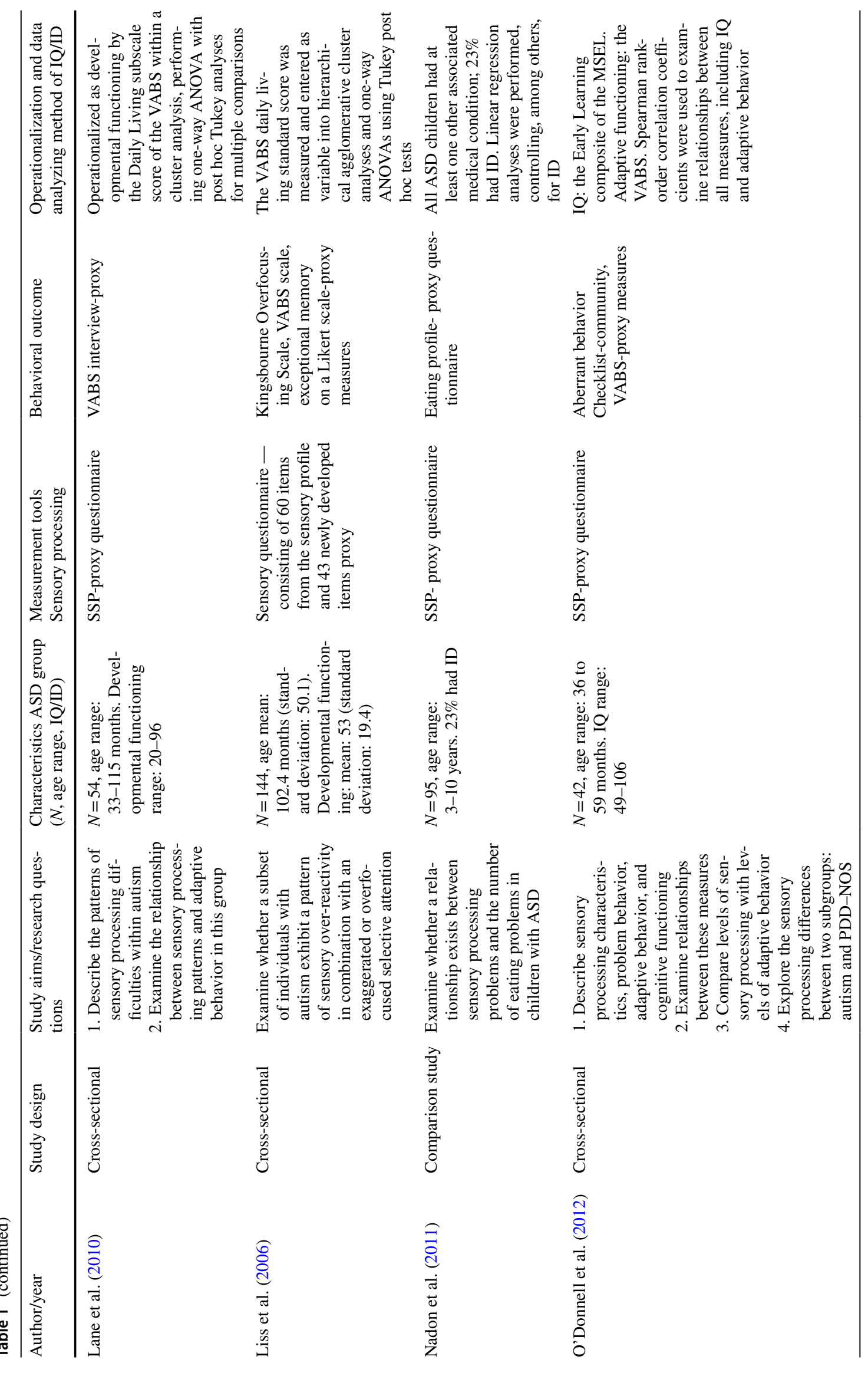




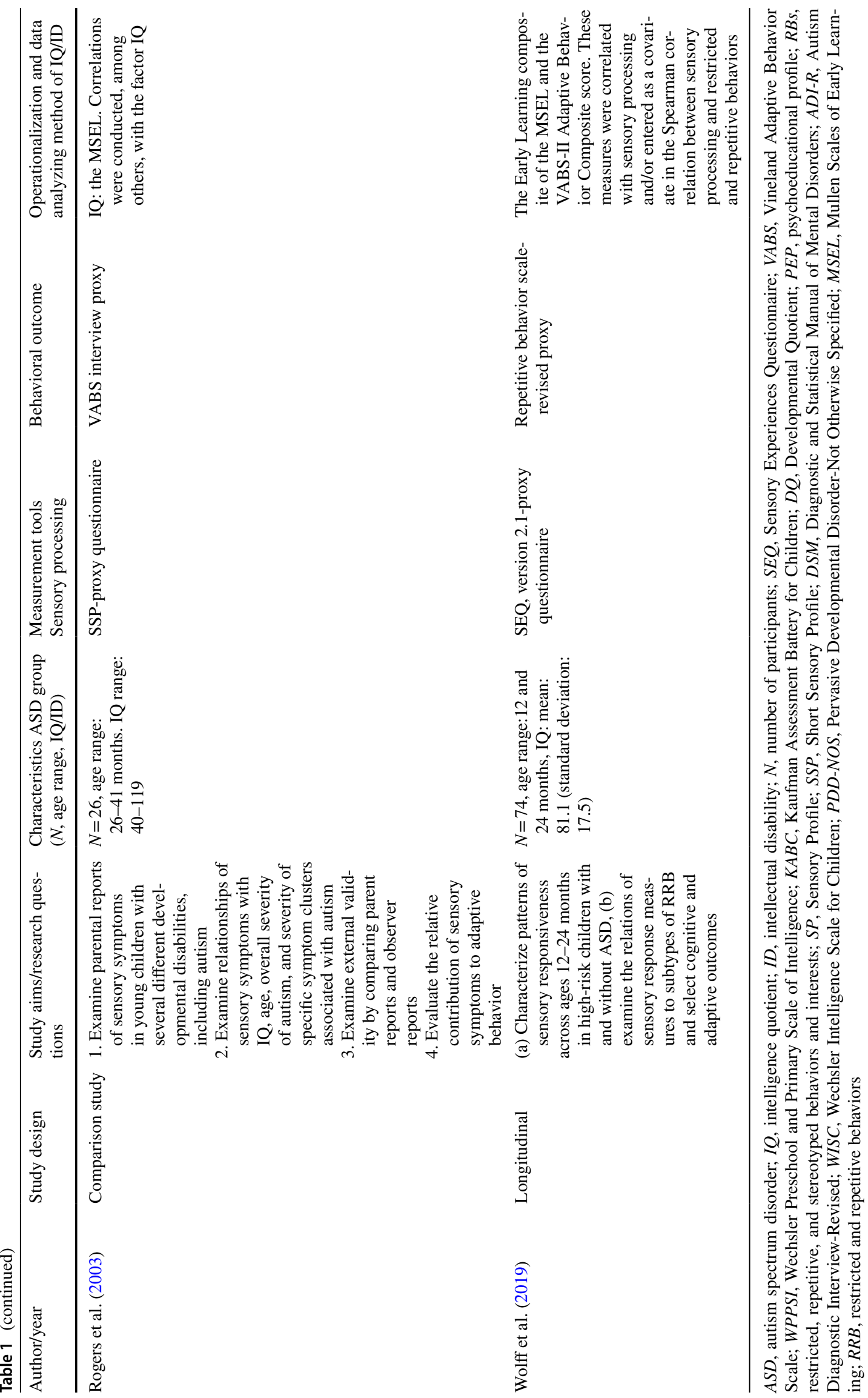


original terminology used to describe ID. In the text, we give a description per aim, ordering papers according to their study characteristics (e.g., measures used, analyzing technique) to explore possible causes of heterogeneity among study results.

\section{Quality of the Included Studies}

Two of the 11 papers had a high risk of bias, meaning that for at least two domains, these papers received a "high" score (Liss et al. 2006; Rogers et al. 2003) (Table 2). All papers had good statistical analysis and reporting. Measurements of sensory processing and behavioral outcomes were mostly of moderate quality, because they included only proxy measurements. Furthermore, for all papers, "study participation" was of low to moderate quality. The "study attrition" received the most "high" scores, followed by the "study confounding," indicating that these factors were most likely to cause bias in the papers concerned.

\section{The Impact of the Presence of ID on Sensory Processing for Individuals with ASD}

In Table 3, we present results of the synthesis of both aim 1, i.e., the impact of the presence of ID on sensory processing in individuals with ASD (reported by 10 of the 11 papers), and aim 2, i.e., the impact of the presence of ID on the relation between sensory processing and behavioral outcomes in individuals with ASD (reported by five of the 11 papers).

Seven papers reported that the presence of ID had no impact on sensory processing (all without IQ cutoff criteria). Green et al. (2016) $(N=116$; age range:10-13.8 years; Short Sensory Profile; and three items of the Autism Diagnostic Interview-Revised), O'Donnell et al. 2012) $(N=42$; age range: 36 to 59 months, Short Sensory Profile), and Rogers et al. (2003) $(N=26$; age range: $26-41$ months, Short Sensory Profile) all found that the presence of ID had no impact on sensory processing in general. The study of Green et al. (2016) was based on regression analysis, and those of O'Donnell et al. (2012) and Rogers et al. (2003) were based on correlation analysis; all three used a range of factors, including ID. Nadon et al. (2011) $(N=95$; age range: $3-10$ years, Short Sensory Profile) and Wolff et al. (2019) $(N=74$; age range: 12 and 24 months, Sensory Experiences Questionnaire) found no impact of the presence of ID on sensory processing, both in general and for the subscores. These studies used linear regression analyses with ID as one of the covariates and Pearson correlations, respectively. Lane et al. (2010) $(N=54$; age range: $33-115$ months, Short Sensory Profile) concluded that the presence of ID had no impact on the categorization of three sensory processing subtypes, based on the seven sensory domain scores: sensory-based inattentive seeking, sensory modulation with movement sensitivity, and sensory modulation with taste/smell sensitivity; their study was based on cluster analysis, among others including ID (operationalized as the Daily Living Subscale), performing a one-way ANOVA with post hoc Tukey analyses for multiple comparisons. Dellapiazza et al. (2020) $(N=197$; age range: $3-10$ years and 11 months, Sensory Profile) found some indications of small effects, but their overall conclusion was that the presence of ID had no impact on sensory processing, based on the Student's $t$-test for parametric variables and the Mann-Whitney test, in both of which ID was entered as one of the variables.

Table 2 Quality assessment of the included papers

\begin{tabular}{|c|c|c|c|c|c|c|c|}
\hline Paper & $\begin{array}{l}\text { Study par- } \\
\text { ticipation }\end{array}$ & Study attrition & $\begin{array}{l}\text { Prognostic factor } \\
\text { measurement }\end{array}$ & $\begin{array}{l}\text { Outcome } \\
\text { measurement }\end{array}$ & $\begin{array}{l}\text { Study con- } \\
\text { founding }\end{array}$ & $\begin{array}{l}\text { Statistical analy- } \\
\text { sis and reporting }\end{array}$ & Overall risk of bias \\
\hline Ausderau et al. (2016) & M & M & M & M & $\mathrm{L}$ & $\mathrm{L}$ & Moderate \\
\hline Dellapiazza et al. (2020) & $\mathrm{L}$ & $\mathrm{H}$ & $\mathrm{L}$ & $\mathrm{L}$ & M & $\mathrm{L}$ & Moderate \\
\hline Gabriels et al. (2008) & M & $\mathrm{H}$ & M & M & $\mathrm{L}$ & $\mathrm{L}$ & Moderate \\
\hline Gonthier et al. (2016) & $\mathrm{L}$ & $\mathrm{L}$ & M & $\mathrm{L}$ & $\mathrm{L}$ & $\mathrm{L}$ & Low \\
\hline Green et al. (2016) & $\mathrm{L}$ & $\mathrm{L}$ & $\mathrm{L}$ & M & $\mathrm{H}$ & $\mathrm{L}$ & Moderate \\
\hline Lane et al. (2010) & M & $\mathrm{H}$ & M & M & M & $\mathrm{L}$ & Moderate \\
\hline Liss et al. (2006) & $\mathrm{L}$ & M & $\mathrm{H}$ & M & $\mathrm{H}$ & $\mathrm{L}$ & High \\
\hline Nadon et al. (2011) & M & $\mathrm{H}$ & $\mathrm{L}$ & $\mathrm{L}$ & M & $\mathrm{L}$ & Moderate \\
\hline O’ Donnell et al. (2012) & M & $\mathrm{L}$ & M & M & $\mathrm{H}$ & $\mathrm{L}$ & Moderate \\
\hline Rogers et al. (2003) & M & $\mathrm{H}$ & $\mathrm{H}$ & M & M & $\mathrm{L}$ & High \\
\hline Wolff et al. (2019) & $\mathrm{L}$ & $\mathrm{H}$ & $\mathrm{L}$ & M & $\mathrm{L}$ & $\mathrm{L}$ & Moderate \\
\hline
\end{tabular}

$L$, low risk of bias; $M$, moderate risk of bias; $H$, high risk of bias 


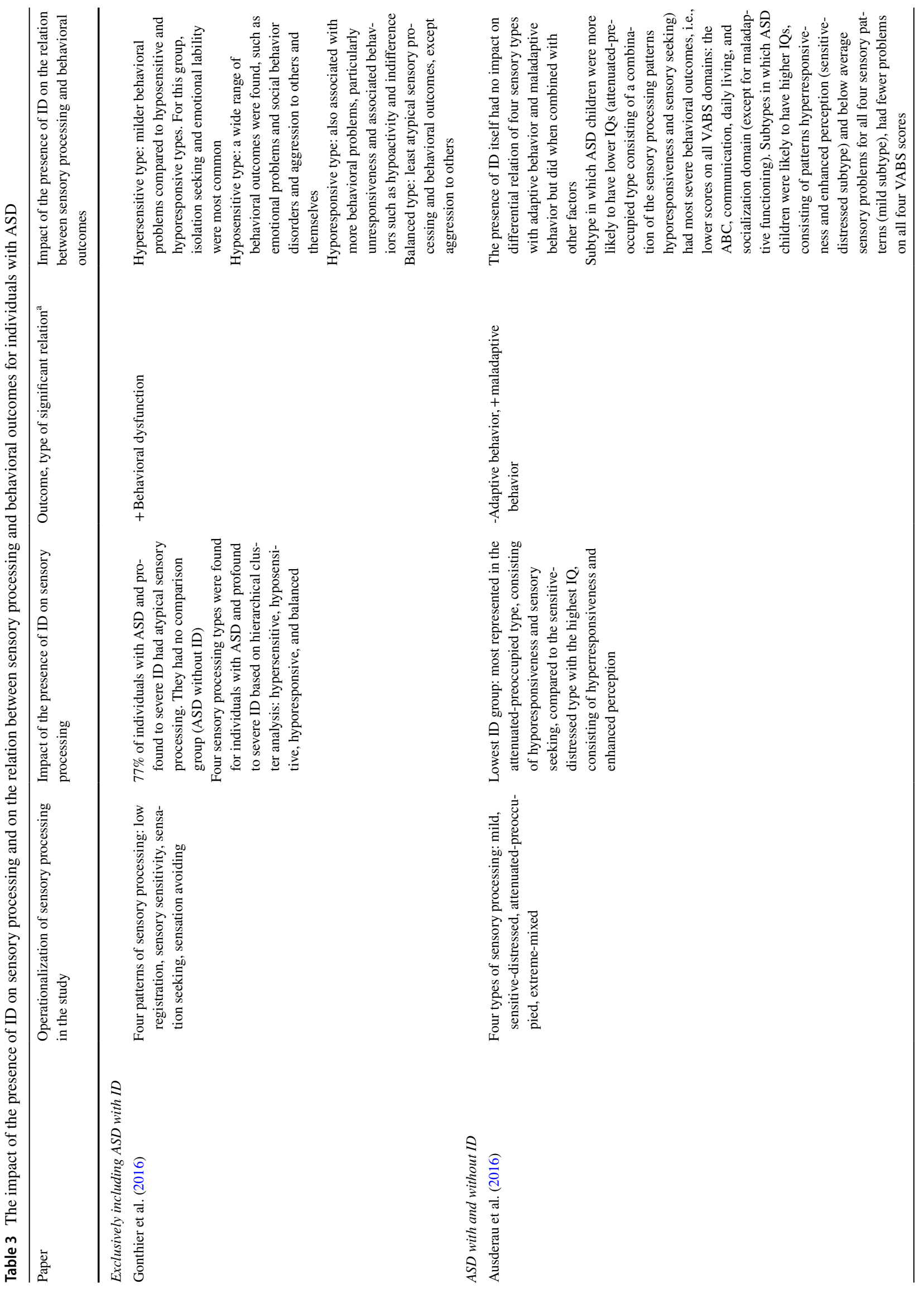




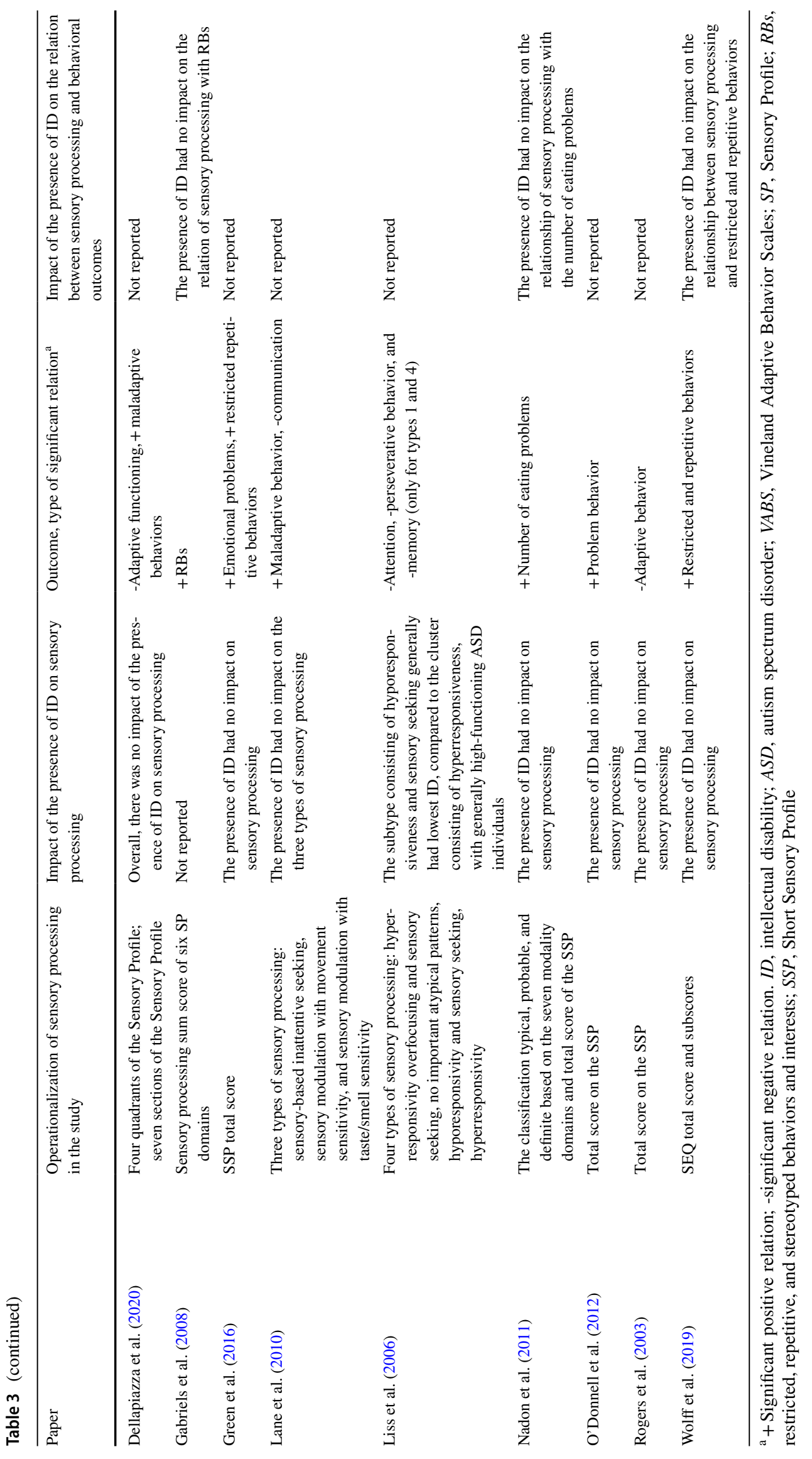


The other three papers found that certain types of sensory processing were more prevalent among individuals with ASD and ID. Gonthier et al. (2016) $(N=148$; age range: 19-59 years, Adolescent/Adult Sensory Profilemodified version) found four subtypes of sensory processing: hypersensitive, hyposensitive, hyporesponsive, and balanced. The hyporesponsive subtype was associated with the lowest and the balanced subtype with the highest verbal levels, indicating that the hyporesponsive subtype involves the most severe group. Gonthier et al. (2016) exclusively included individuals with ASD and profound to severe ID (318.1 or 318.2 DSM-IV TR), living in care centers (no comparison group), and performed hierarchical cluster analysis to identify distinct sensory subtypes. The subtypes were based on the patterns hyperresponsiveness, hyporesponsiveness, sensory seeking, and sensory avoiding. Ausderau et al. (2016) and Liss et al. (2006) also found four different subtypes of sensory processing in their sample. Both Ausderau et al. (2016) $(N=960$; age range: $2-12$ years, Sensory Experiences Questionnaire 3.0) (without an IQ cutoff) and Liss et al. (2006) $(N=144$; age mean: 102.4 months, standard deviation: 50.1, Sensory Questionnaire consisting of 60 items from the Sensory Profile and 43 newly developed items) reported that one sensory processing subtype involving hyporesponsiveness and sensory seeking was related to the lowest ID. In addition, Ausderau et al. (2016) reported that a subtype involving the patterns hyperresponsiveness and enhanced perception was related to the highest IQ (2016), for Liss et al. (2006), the highest developmental functioning was related to hyperresponsiveness. Furthermore, Ausderau et al. (2016) found that of the four subtypes of sensory processing, two were positively associated with ID: the sensitive distressed subtype, which entails the sensory patterns hyperresponsiveness and enhanced perception, and the extreme-mixed subtype, consisting of high sensory problems across the sensory patterns hyporesponsiveness, hyperresponsiveness, sensory seeking, and enhanced perception. The mild subtype, which entails below average sensory problems for all four sensory patterns, and an attenuated-preoccupied subtype, consisting of more hyporesponsiveness and sensory seeking, were negatively associated with ID. This indicates that ASD children in the first two subtypes were more likely to have higher IQs, whereas those in the last two subtypes more likely had lower IQs. Ausderau et al. (2016) analyzed four distinct sensory subtypes found prior to this analysis, using a regression model in which ID was a covariate. The subtypes were developed based on hyperresponsiveness, hyporesponsiveness, sensory seeking, and enhanced perception patterns. Liss et al. (2006) operationalized ID as developmental functioning, based on the Vineland daily living standard score without an IQ cutoff. They performed cluster analyses based on a variety of variables, to determine the impact of the presence of ID, using the patterns hyperreactivity, hyporeactivity, and sensory seeking regarding sensory processing.

\section{The Impact of the Presence of ID on the Relation Between Sensory Processing and Behavioral Outcomes for Individuals with ASD}

Three papers found the presence of ID (without IQ cutoff) to have no impact. Gabriels et al. (2008) $(N=70$; age range: 3-19.7 years, Sensory Profile) concluded that the presence of ID had no impact on the association between overall sensory processing and behavioral outcomes (defined as restricted, repetitive, and stereotyped behaviors and interests (RBs)), based on a correlation analysis including control for ID. The other two papers (Nadon et al. 2011, and Wolff et al. 2019) found the presence of ID to have no impact on the association of overall sensory processing and sensory subscores with behavioral outcomes. Nadon et al. (2011) $(N=95$; age range: 3-10 years, Short Sensory Profile) performed linear regression, including control for ID, to determine the association between sensory processing and the number of eating problems. Wolff et al. (2019) $(N=74$; age range: 12 and 24 months) used the Sensory Experiences Questionnaire and performed Spearman correlations controlling for ID to determine the association between sensory processing and restricted and repetitive behaviors.

Two papers found some impact of the presence of ID on the relation between sensory processing and behavioral outcomes. Gonthier et al. (2016) $(N=148$; age range: 19-59 years, Adolescent/Adult Sensory Profilemodified version) included only individuals with both ASD and profound to severe ID (318.1 or 318.2 DSMIV TR) living in care centers (no comparison group); they concluded that the presence of ID had an impact on the relation between four sensory processing subtypes and different behavioral outcomes. In particular, the hyposensitive and hyporesponsive subtypes were associated with the most severe behavioral outcomes: with the hyposensitive subtype, a wide range of behavioral outcomes such as emotional problems, social behavior disorders, and aggression to others and themselves, and with the hyporesponsive subtype, e.g., unresponsiveness, hypoactivity, and indifference. The hypersensitive 
and balanced types were associated with normal to mild behavioral outcomes on almost all behavioral disorders. Gonthier et al. (2016) performed bivariate correlations and ANOVAs and, where applicable, post hoc comparisons, using Fisher's least significant difference to assess the association between sensory processing and behavioral outcomes. Ausderau et al. (2016) $(N=960$; age range: $2-12$ years, Sensory Experiences Questionnaire 3.0) (without an IQ cutoff) also found sensory processing subtypes to be related to different behavioral outcomes. The subtype in which ASD children were more likely to have lower IQs (consisting of a combination of the sensory processing patterns hyporesponsiveness and sensory seeking) was related to the most severe behavioral outcomes, i.e., lower scores on all Vineland Adaptive Behavior Scales domains: the ABC, communication, daily living, and socialization domains (except for maladaptive functioning). The subtypes in which the ASD children were likely to have higher IQs, consisting of the patterns hyperresponsiveness and enhanced perception (sensitive-distressed subtype) and below average sensory problems for all four sensory patterns (mild subtype), had fewer problems according to all four Vineland Adaptive Behavior Scales scores. Ausderau et al. (2016) performed simple pairwise comparisons between four previously found distinct sensory subtypes (differing in level of IQ) and the different VABS domains.

All 11 included papers investigated the relation between sensory processing and behavioral outcomes. Five focused on how the presence of ID impacted the relation between sensory processing and behavioral outcomes. Of these five, one investigated both internalizing and externalizing behavior (Gonthier et al. 2016), two studied externalizing behavior (Gabriels et al. 2008; Wolff et al. 2019), and no paper investigated social participation. Two papers investigated other behavioral outcomes: adaptive behavior (Ausderau et al. 2016), and number of eating problems (Nadon et al. 2011).

Regarding the quality assessment, findings were similar, both when including only the high-quality papers and when including only the papers with the greatest risk of bias.

\section{Discussion}

In this review, seven studies reported that the presence of ID had no impact on overall sensory processing and sensory processing subscores, and three concluded that subtypes consisting of more hyporesponsiveness and sensory seeking were associated with ASD individuals with
ID. Next, five studies found that the presence of ID did not impact the relation of sensory processing in general and sensory subscores with behavioral outcomes for individuals with ASD. Two studies found that the presence of ID impacted the relation between sensory processing and behavioral outcomes when subtypes were assessed based on hyperresponsiveness and hyporesponsiveness; the latter had the poorest outcomes. More specifically, the subtypes based on hyporesponsiveness were associated with a range of behavioral outcomes, including less adaptive functioning and different patterns of behavioral dysfunction and behavioral disorders, such as hypoactivity and indifference.

Although seven studies reported no impact of the presence of ID on sensory processing, three studies did report an impact. The seven studies that reported no impact dealt with overall sensory processing and most separate subscores, whereas the studies that did find an impact dealt with subtypes consisting of more hyporesponsiveness and sensory seeking. These contradictory findings on the impact of ID are in line with the review of Hazen et al. (2014), which showed heterogeneous findings about the role of IQ on sensory processing in individuals with ASD. A possible explanation for our findings may be, first, that the presence of ID has a diverse impact on sensory processing. Second, the contrasting findings could be related to heterogeneity among the characteristics of the studies, although age, IQ cutoffs, or types of measures did not play a role here. Sample sizes were slightly higher for the studies finding an impact. Therefore, a more plausible explanation could be that using average scores of sensory processing, or analyzing subscores separately, gave a distorted view, since operationalization in subtypes combining different subscores or factors based on hyper- and hyporesponsiveness patterns showed that the presence of ID did have an impact. Development of a generally accepted taxonomy of sensory processing is needed to adequately assess the sensory processing of individuals with ASD and ID, using as starting point a categorization based on hyperresponsiveness and hyporesponsiveness.

Studies based on overall sensory processing and sensory processing subscores found no impact of the presence of ID on the association between sensory processing and behavioral outcomes, whereas two studies found subtypes of sensory processing based on hyperresponsiveness and hyporesponsiveness to be related to ID and the subtypes based on hyporesponsiveness to be associated with the poorest outcomes. These contradictory findings correspond with the review of Schauder and Bennetto 
(2016), which reported diverse associations between sensory processing patterns and behavioral outcomes within the ASD population. A possible explanation for our findings could be that the presence of ID has a diverse impact on the association between sensory processing and behavioral outcomes. Moreover, differences could be due to study characteristics. However, studies did not differ in their reported study characteristics, except that those based on a higher sample size reported the presence of ID as having an impact. A more plausible explanation could be that using overall scores, or separately analyzing subscores, confounded the relationship. Analysis of subtypes of sensory processing in which different subscores were combined found some impact of the presence of ID. More research into the impact of the presence of ID, and particularly into subtypes of sensory processing, is needed to further predict outcomes in clinical practice.

Researchers found no impact of the presence of ID when using only total scores, subscores, or subtypes based on the domain scores. In contrast, a categorization into subtypes based on hyperresponsiveness and hyporesponsiveness showed an impact of the presence of ID on sensory processing (aim 1) and on the relation between sensory processing and behavioral outcomes (aim 2) in individuals with ASD. These findings suggest a need for more research into the impact of the presence of ID on the sensory processing of ASD individuals. Also, a classification of sensory processing subtypes, built upon the subdivisions hyper- and hyporesponsiveness, could be developed for further assessment of differences in the presence of ID.

Of all the included studies, none had the primary aim to investigate the presence of ID on sensory processing and/or whether the presence of ID impacted the association between sensory processing and behavioral outcomes within the ASD population. This indicates a need for future studies focused primarily on the impact of the presence of ID to fully grasp this topic.

The papers included in our review varied in quality. However, in studies with a high risk of bias compared to studies with a low risk of bias, findings were similar. For some of the included papers, specific domains of the quality assessment tool were not fully applicable. More specifically, the domain "study attrition" was most frequently "not applicable" to the included studies. The heterogeneity of the findings could thus be related to the content, and not to a difference in quality, between the included papers.
Our review has several strengths. First, we included studies using only individuals with ASD and ID in their sample, as well as studies using mixed samples of ASD individuals with and without ID. Second, we did not restrict our review to a certain age range or to only one categorization or type of measurement of sensory processing. Third, for papers that did not report the ID values of their sample, authors were contacted, and papers were in- or excluded based on their information.

Nevertheless, our review has some limitations. First, we had strict in- and exclusion criteria, which could have led to exclusion of some papers which may appear to meet the inclusion criteria. In particular, during our title/ abstract selection, we excluded papers that focused on sensory processing without a link with behavioral outcomes. Therefore, we may have missed papers giving more information about the impact of the presence of ID on sensory processing in individuals with ASD (our first aim). Second, we defined an ID as either low adaptive functioning or low intelligence functioning. This may have led to the inclusion of some respondents who did not fully meet the DSM-5 criteria for ID (American Psychiatric Association, 2013), potentially a somewhat less severely affected group.

First, we found that most studies reported no impact of the presence of ID, whereas a few studies did, based on subtypes. Thus careful attention should be paid to an individualized sensory processing analysis, using sensory processing problems rather than level of functioning as starting point. Second, our findings that only certain subtypes of sensory processing among individuals with ASD and ID are associated with severe behavioral outcomes imply that these subtypes should be more definitely determined in clinical practice in order to establish a prognosis. Moreover, information on subtypes of sensory processing is needed, since the impact of the presence of ID was missed when average scores or subscores were compared. Third, sensory processing and related behavioral outcomes could best be assessed through analyzing a person's behavior. This implies that proxy questionnaires and other measurement tools, like observation, should be combined in routine practice to obtain more reliable evidence on how the presence of ID impacts sensory processing and related behavioral outcomes. This is particularly important, because interpretation of behavior (including sensory processing) of individuals functioning at lower developmental levels is more complex.

First, further research into the specific impact of the presence of ID on sensory processing subtypes among 
individuals with ASD and ID is needed for development of a sensory processing taxonomy. This should include the relation of sensory processing with behavioral outcomes for individuals with both ASD and ID. Second, more longitudinal research on individuals with both ASD and ID is needed, particularly in older children, adolescents, and adults. Third, most of the included studies used parent questionnaires to assess sensory processing and behavioral outcomes. Future studies should use more observational and objective measurements. This will not only strengthen the reliability of the data collection method but also reduce the risk of bias. Lastly, more research is needed about the relation between sensory processing and broader behavioral outcomes, as overlapping symptoms could represent one underlying mechanism, especially in younger children and individuals functioning at lower developmental levels (Gillberg, 2010). In particular, the impact of the presence of ID on the association between sensory processing and social participation in individuals with ASD should be investigated, since this has not as yet been studied. In contrast, on a more fundamental level, ID and ASD probably have different underlying pathophysiological mechanisms. Future research should, therefore, include a physiological perspective on sensory processing problems and associated outcomes. Even though symptoms on different developmental domains are quite similar in both disorders (Gillberg, 2010), the underlying mechanisms of each disorder may be different and are not yet fully understood (Kroon et al. 2013).

In summary, our review showed contrasting findings regarding the impact of the presence of ID. On the one hand, papers based on overall sensory processing and most separate sensory subscores found no impact of ID on sensory processing and its association with behavioral outcomes. On the other hand, papers studying subtypes based on hyperresponsiveness and hyporesponsiveness in individuals with ASD found subtypes consisting of hyporesponsiveness and sensory seeking to be associated with the presence of ID and hyporesponsiveness to be associated with the most severe behavioral outcomes. In-depth analysis of sensory processing is needed to further assess sensory processing and its association with behavioral outcomes in individuals with both ASD and ID. In particular, operationalizing sensory processing into subtypes based, among others, on the level of ID could help us to better grasp sensory patterns and outcomes, resulting in greater knowledge of how to support individuals with both ASD and ID.

\section{Appendix A}

\section{Search strategies}

For all three databases: publications from 2000.

Pubmed:

("Sensory Gating"[Mesh] OR sensory*[TI] OR habituation[TI] OR (response[TI] AND input[TI]) OR (reactivity [TI] AND input[TI]) OR hypo-respon*[TI] OR hyper-respon*[TI] OR hyporespon*[TI] OR hyperrespon*[TI] OR overrespon*[TI] OR over-respon*[TI] OR underrespon*[TI] OR under-respon*[TI]) AND ("Child Development Disorders, Pervasive"[Mesh] OR autism spectrum disorder*[TIAB] OR autis*[TIAB] OR $A S D$ [TIAB] OR asperger[TIAB] OR pervasive developmental disorder*[TIAB] OR pervasive development disorder*[TIAB]) NOT (animal NOT human) Filters: Publication date from 2000/01/01.

PsycINFO:

( (DE "Sensory Gating" OR TI (sensory* OR habituation OR response N5 input OR reactivity N5 input OR hyporespon* OR hyper-respon* OR hyporespon* OR hyperrespon* OR overrespon* OR over-respon* OR underrespon* OR under-respon*)) AND ( (DE "Autism Spectrum Disorders" OR TI(autis* OR ASD OR asperger OR pervasive developmental disorder* OR pervasive development disorder*) OR AB(autis* OR ASD OR asperger OR pervasive developmental disorder* OR pervasive development disorder*))) NOT PO ( animal NOT human).

ERIC:

( (DE "Sensory Experience" OR (TI (sensory* OR habituation OR response N5 input OR reactivity N5 input OR hypo-respon* OR hyper-respon* OR hyporespon* OR hyperrespon* OR overrespon* OR over-respon* OR underrespon* OR und.er-respon*)) ) AND ( (DE "Pervasive Developmental Disorders" OR DE "Asperger Syndrome" OR DE "Autism" OR (TI ( autis* OR ASD OR asperger OR "pervasive developmental disorder*" OR "pervasive development disorder*") OR AB (autis* OR ASD OR asperger OR "pervasive developmental disorder*" OR "pervasive development disorder*”))))

Date of search: May 18, 2020.

\section{Appendix B}

Completed PRISMA 2009 Checklist 


\begin{tabular}{|c|c|c|c|}
\hline Section/topic & \# & Checklist item & Page \\
\hline \multicolumn{4}{|l|}{ TITLE } \\
\hline Title & 1 & Identify the report as a systematic review, meta-analysis, or both. & 1 \\
\hline \multicolumn{4}{|l|}{ ABSTRACT } \\
\hline Structured summary & 2 & $\begin{array}{l}\text { Provide a structured summary including, as applicable: background; } \\
\text { objectives; data sources; study eligibility criteria, participants, and } \\
\text { interventions; study appraisal and synthesis methods; results; } \\
\text { limitations; conclusions and implications of key findings; systematic } \\
\text { review registration number. }\end{array}$ & 1 \\
\hline \multicolumn{4}{|l|}{ INTRODUCTION } \\
\hline Rationale & 3 & $\begin{array}{l}\text { Describe the rationale for the review in the context of what is already } \\
\text { known. }\end{array}$ & 2,3 \\
\hline Objectives & 4 & $\begin{array}{l}\text { Provide an explicit statement of questions being addressed with } \\
\text { reference to participants, interventions, comparisons, outcomes, and } \\
\text { study design (PICOS). }\end{array}$ & 4 \\
\hline \multicolumn{4}{|l|}{ METHODS } \\
\hline $\begin{array}{l}\text { Protocol and } \\
\text { registration }\end{array}$ & 5 & $\begin{array}{l}\text { Indicate if a review protocol exists, if and where it can be accessed } \\
\text { (e.g., Web address), and, if available, provide registration information } \\
\text { including registration number. }\end{array}$ & 4/App. B \\
\hline Eligibility criteria & 6 & $\begin{array}{l}\text { Specify study characteristics (e.g., PICOS, length of follow-up) and } \\
\text { report characteristics (e.g., years considered, language, publication } \\
\text { status) used as criteria for eligibility, giving rationale. }\end{array}$ & 4,5 \\
\hline Information sources & 7 & $\begin{array}{l}\text { Describe all information sources (e.g., databases with dates of coverage, } \\
\text { contact with study authors to identify additional studies) in the search } \\
\text { and date last searched. }\end{array}$ & 4 \\
\hline Search & 8 & $\begin{array}{l}\text { Present full electronic search strategy for at least one database, } \\
\text { including any limits used, such that it could be repeated. }\end{array}$ & App. A \\
\hline Study selection & 9 & $\begin{array}{l}\text { State the process for selecting studies (i.e., screening, eligibility, } \\
\text { included in systematic review, and, if applicable, included in the meta- } \\
\text { analysis). }\end{array}$ & 4,5 \\
\hline Data collection process & 10 & $\begin{array}{l}\text { Describe method of data extraction from reports (e.g., piloted forms, } \\
\text { independently, in duplicate) and any processes for obtaining and } \\
\text { confirming data from investigators. }\end{array}$ & 4,5 \\
\hline Data items & 11 & $\begin{array}{l}\text { List and define all variables for which data were sought (e.g., PICOS, } \\
\text { funding sources) and any assumptions and simplifications made. }\end{array}$ & 5/App. A \\
\hline $\begin{array}{l}\text { Risk of bias in } \\
\text { individual studies }\end{array}$ & 12 & $\begin{array}{l}\text { Describe methods used for assessing risk of bias of individual studies } \\
\text { (including specification of whether this was done at the study or } \\
\text { outcome level), and how this information is to be used in any data } \\
\text { synthesis. }\end{array}$ & 5,6 \\
\hline Summary measures & 13 & $\begin{array}{l}\text { State the principal summary measures (e.g., risk ratio, difference in } \\
\text { means). }\end{array}$ & NA \\
\hline Synthesis of results & 14 & $\begin{array}{l}\text { Describe the methods of handling data and combining results of } \\
\text { studies, if done, including measures of consistency }\left(\mathrm{e} . \mathrm{g} ., \mathrm{I}^{2}\right) \text { for each } \\
\text { meta-analysis. }\end{array}$ & NA \\
\hline $\begin{array}{l}\text { Risk of bias across } \\
\text { studies }\end{array}$ & 15 & $\begin{array}{l}\text { Specify any assessment of risk of bias that may affect the cumulative } \\
\text { evidence (e.g., publication bias, selective reporting within studies). }\end{array}$ & NA \\
\hline Additional analyses & 16 & $\begin{array}{l}\text { Describe methods of additional analyses (e.g., sensitivity or subgroup } \\
\text { analyses, meta-regression), if done, indicating which were pre- } \\
\text { specified. }\end{array}$ & NA \\
\hline \multicolumn{4}{|l|}{ RESULTS } \\
\hline Study selection & 17 & $\begin{array}{l}\text { Give numbers of studies screened, assessed for eligibility, and } \\
\text { included in the review, with reasons for exclusions at each stage, } \\
\text { ideally with a flow diagram. }\end{array}$ & 6/Fig. 1 \\
\hline Study characteristics & 18 & $\begin{array}{l}\text { For each study, present characteristics for which data were extracted } \\
\text { (e.g., study size, PICOS, follow-up period) and provide the citations. }\end{array}$ & $\begin{array}{l}6,7 / \text { Table } \\
1\end{array}$ \\
\hline $\begin{array}{l}\text { Risk of bias within } \\
\text { studies }\end{array}$ & 19 & $\begin{array}{l}\text { Present data on risk of bias of each study and, if available, any } \\
\text { outcome level assessment (see item 12). }\end{array}$ & 7/Table 2 \\
\hline $\begin{array}{l}\text { Results of individual } \\
\text { studies }\end{array}$ & 20 & $\begin{array}{l}\text { For all outcomes considered (benefits or harms), present, for each } \\
\text { study: (a) simple summary data for each intervention group (b) effect } \\
\text { estimates and confidence intervals, ideally with a forest plot. }\end{array}$ & NA \\
\hline Synthesis of results & 21 & $\begin{array}{l}\text { Present results of each meta-analysis done, including confidence } \\
\text { intervals and measures of consistency. }\end{array}$ & NA \\
\hline $\begin{array}{l}\text { Risk of bias across } \\
\text { studies }\end{array}$ & 22 & $\begin{array}{l}\text { Present results of any assessment of risk of bias across studies (see } \\
\text { Item 15). }\end{array}$ & NA \\
\hline Additional analysis & 23 & $\begin{array}{l}\text { Give results of additional analyses, if done (e.g., sensitivity or } \\
\text { subgroup analyses, meta-regression [see Item 16]). }\end{array}$ & NA \\
\hline \multicolumn{4}{|l|}{ DISCUSSION } \\
\hline Summary of evidence & 24 & $\begin{array}{l}\text { Summarize the main findings including the strength of evidence for } \\
\text { each main outcome; consider their relevance to key groups (e.g., } \\
\text { healthcare providers, users, and policy makers). }\end{array}$ & $\begin{array}{l}11,12 \\
13,14\end{array}$ \\
\hline Limitations & 25 & $\begin{array}{l}\text { Discuss limitations at study and outcome level (e.g., risk of bias), and } \\
\text { at review-level (e.g., incomplete retrieval of identified research, } \\
\text { reporting bias). }\end{array}$ & 13 \\
\hline Conclusions & 26 & $\begin{array}{l}\text { Provide a general interpretation of the results in the context of other } \\
\text { evidence, and implications for future research. }\end{array}$ & $\begin{array}{l}11,12 \\
13,14 \\
\end{array}$ \\
\hline \multicolumn{4}{|l|}{ FUNDING } \\
\hline Funding & 27 & $\begin{array}{l}\text { Describe sources of funding for the systematic review and other } \\
\text { support (e.g., supply of data); role of funders for the systematic } \\
\text { review. }\end{array}$ & Title page \\
\hline
\end{tabular}


Acknowledgements We would like to thank ZonMw (grant number 845004006) for funding this research project.

Author contribution MFW coordinated the study, was involved in the design, data collection, and interpretation of the study, and wrote the manuscript. JAL was involved in the design, data collection, and interpretation and the drafting process of the manuscript. ASF was involved in the data collection and at the first and last stage of writing the manuscript and advised during the whole process. YMD was involved in the first and last stage of writing the manuscript and advised during the whole process. IAB was involved in the first and last stage of writing the manuscript and advised during the whole process. SB was involved in the design and interpretation of study and the drafting process of the manuscript. SAR was involved in the design and interpretation of the study and the drafting process of the manuscript. All authors reviewed the final version and agreed with its submission.

\section{Declarations}

Ethics Approval This article does not contain any studies with human participants or animals performed by any of the authors.

\section{Consent to Participate Not applicable}

Funding ZonMw,845004006,J.A. Landsman

Conflict of Interest The authors declare no competing interests.

Open Access This article is licensed under a Creative Commons Attribution 4.0 International License, which permits use, sharing, adaptation, distribution and reproduction in any medium or format, as long as you give appropriate credit to the original author(s) and the source, provide a link to the Creative Commons licence, and indicate if changes were made. The images or other third party material in this article are included in the article's Creative Commons licence, unless indicated otherwise in a credit line to the material. If material is not included in the article's Creative Commons licence and your intended use is not permitted by statutory regulation or exceeds the permitted use, you will need to obtain permission directly from the copyright holder. To view a copy of this licence, visit http://creativecommons.org/licenses/by/4.0/.

\section{References}

American Psychiatric Association. (2013). Diagnostic and statistical manual of mental disorders (5th ed.). Author.

Ashburner, J., Ziviani, J., \& Rodger, S. (2008). Sensory processing and classroom emotional, behavioral, and educational outcomes in children with autism spectrum disorder. American Journal of Occupational Therapy, 62(5), 564-573. https://doi.org/10.5014/ ajot.62.5.564

Ausderau, K., Sideris, J., Furlong, M., Little, L., Bulluck, J., \& Baranek, G. (2014). National survey of sensory features in children with ASD: Factor structure of the sensory experience questionnaire (3.0). Journal of Autism \& Developmental Disorders, 44(4), 915-925. https://doi.org/10.1007/s10803-013-1945-1

Ausderau, K. K., Sideris, J., Little, L. M., Furlong, M., Bulluck, J. C., \& Baranek, G. T. (2016). Sensory subtypes and associated outcomes in children with autism spectrum disorders. Autism Research: Official Journal of the International Society for Autism Research, 9(12), 1316-1327. https://doi.org/10.1002/aur.1626

Baranek, G. T., David, F. J., Poe, M. D., Stone, W. L., \& Watson, L. R. (2006). Sensory Experiences Questionnaire: Discriminating sensory features in young children with autism, developmental delays, and typical development. Journal of Child Psychology and Psychiatry, 47(6), 591-601. https://doi.org/10.1111/j.14697610.2005.01546.x

Baranek, G. T., Watson, L. R., Boyd, B. A., Poe, M. D., David, F. J., \& McGuire, L. (2013). Hyporesponsiveness to social and nonsocial sensory stimuli in children with autism, children with developmental delays, and typically developing children. Development and Psychopathology, 25(2), 307-320. https://doi.org/10.1017/ S0954579412001071

Ben-Sasson, A., Cermak, S. A., Orsmond, G. I., Tager-Flusberg, H., Carter, A. S., Kadlec, M. B., \& Dunn, W. (2007). Extreme sensory modulation behaviors in toddlers with autism spectrum disorders. American Journal of Occupational Therapy, 61(5), 584-592. https://doi.org/10.5014/ajot.61.5.584

Ben-Sasson, A., Gal, E., Fluss, R., Katz-Zetler, N., \& Cermak, S. A. (2019). Update of a meta-analysis of sensory symptoms in ASD: A new decade of research. Journal of Autism and Developmental Disorders, 49(12), 4974-4996. https://doi.org/10.1007/ s10803-019-04180-0

Bitsika, V., Sharpley, C. F., \& Mills, R. (2016). Are sensory processing features associated with depressive symptoms in boys with an ASD? Journal of Autism and Developmental Disorders, 46(1), 242-252. https://doi.org/10.1007/s10803-015-2569-4

Campbell, S. B., Shaw, D. S., \& Gilliom, M. (2000). Early externalizing behavior problems: Toddlers and preschoolers at risk for later maladjustment. Development and Psychopathology, 12(3), 467-488. https://doi.org/10.1017/S0954579400003114

Dellapiazza, F., Michelon, C., Oreve, M. J., Robel, L., Schoenberger, M., Chatel, C., ... ELENA study group. (2020). The impact of atypical sensory processing on adaptive functioning and maladaptive behaviors in autism spectrum disorder during childhood: Results from the ELENA cohort. Journal of Autism and Developmental Disorders, 50(6), 2142-2152. doi:https://doi.org/10.1007/ s10803-019-03970-w

Dunn, W. (1999). Sensory Profile. The psychological corporation.

Eisenberg, N., Cumberland, A., Spinrad, T. L., Fabes, R. A., Shepard, S. A., Reiser, M., . . G Guthrie, I. K. (2001). The relations of regulation and emotionality to children's externalizing and internalizing problem behavior. Child Development, 72(4), 1112. doi: https://doi.org/10.1111/1467-8624.00337

Engel-Yeger, B., Hardal-Nasser, R., \& Gal, E. (2011). Sensory processing dysfunctions as expressed among children with different severities of intellectual developmental disabilities. Research in Developmental Disabilities, 32(5), 1770-1775. https://doi.org/10. 1016/j.ridd.2011.03.005

Fetta, A., Carati, E., Moneti, L., Pignataro, V., Angotti, M., Bardasi, M.C., ... Parmeggiani, A. (2021). Relationship between sensory alterations and repetitive behaviours in children with autism spectrum disorders: A parents' questionnaire based study. Brain Sciences, 11(4), 484. doi:https://doi.org/10.3390/brainsci11040484

Gabriels, R. L., Agnew, J. A., Miller, L. J., Gralla, J., Pan, Z., Goldson, E., . . Hooks, E. (2008). Is there a relationship between restricted, repetitive, stereotyped behaviors and interests and abnormal sensory response in children with autism spectrum disorders? Research in Autism Spectrum Disorders, 2(4), 660-670. doi: https://doi.org/10.1016/j.rasd.2008.02.002

Gillberg, C. (2010). The ESSENCE in child psychiatry: Early symptomatic syndromes eliciting neurodevelopmental clinical examinations. Research in Developmental Disabilities, 31(6), 1543-1551. https://doi.org/10.1016/j.ridd.2010.06.002

Gonthier, C., Longuépée, L., \& Bouvard, M. (2016). Sensory processing in low-functioning adults with autism spectrum disorder: Distinct sensory profiles and their relationships with behavioral dysfunction. Journal of Autism and Developmental Disorders, 46(9), 3078-3089. https://doi.org/10.1007/s10803-016-2850-1 
Gottesman, I. I., \& Gould, T. D. (2003). The endopheno type concept in psychiatry: Etymology and strategic intentions. The American Journal of Psychiatry, 160(4), 636-645. https://doi.org/10.1176/ appi.ajp.160.4.636

Green, D., Chandler, S., Charman, T., Simonoff, E., \& Baird, G. (2016). Brief report: DSM-5 sensory behaviours in children with and without an autism spectrum disorder. Journal of Autism and Developmental Disorders, 46(11), 3597-3606. https://doi.org/10. 1007/s10803-016-2881-7

Hayden, J. A., Van der Windt, D. A., Cartwright, J. L., Côté, P., \& Bombardier, C. (2013). Assessing bias in studies of prognostic factors. Annals of Internal Medicine, 158(4), 280-286. https://doi. org/10.7326/0003-4819-158-4-201302190-00009

Hazen, E. P., Stornelli, J. L., O'Rourke, J. A., Koesterer, K., \& McDougle, C. J. (2014). Sensory symptoms in autism spectrum disorders. Harvard Review of Psychiatry, 22(2), 112-124. https://doi.org/10. 1097/01.HRP.0000445143.08773.58

Hochhauser, M., \& Engel-Yeger, B. (2010). Sensory processing abilities and their relation to participation in leisure activities among children with high-functioning autism spectrum disorder (HFASD). Research in Autism Spectrum Disorders, 4(4), 746754. https://doi.org/10.1016/j.rasd.2010.01.015

Humphry, R. (2002). Young children's occupations: Explicating the dynamics of developmental processes. The American Journal of Occupational Therapy: Official Publication of the American Occupational Therapy Association, 56(2), 171-179. https://doi. org/10.5014/ajot.56.2.171

Ismael, N., Lawson, L. M., \& Hartwell, J. (2018). Relationship between sensory processing and participation in daily occupations for children with autism spectrum disorder: A systematic review of studies that used Dunn's sensory processing framework. American Journal of Occupational Therapy, 72(3), 7203205030p1-7203205030p9. doi: https://doi.org/10.5014/ajot. 2018.024075

Joosten, A. V., \& Bundy, A. C. (2010). Sensory processing and stereotypical and repetitive behaviour in children with autism and intellectual disability. Australian Occupational Therapy Journal, 57(6), 366-372. https://doi.org/10.1111/j.1440-1630.2009. 00835.x

Jussila, K., Junttila, M., Kielinen, M., Ebeling, H., Joskitt, L., Moilanen, I., \& Mattila, M. L. (2020). Sensory abnormality and quantitative autism traits in children with and without autism spectrum disorder in an epidemiological population. Journal of Autism and Developmental Disorders, 50(1), 180-188. https://doi.org/10. 1007/s10803-019-04237-0

Kroon, T., Sierksma, M. C., \& Meredith, R. M. (2013). Investigating mechanisms underlying neurodevelopmental phenotypes of autistic and intellectual disability disorders: A perspective. Frontiers in Systems Neuroscience, 7, 75. https://doi.org/10.3389/fnsys.2013. 00075

Lane, A. E., Young, R. L., Baker, A. E. Z., \& Angley, M. T. (2010). Sensory processing subtypes in autism: Association with adaptive behavior. Journal of Autism and Developmental Disorders, 40(1), 112-122. https://doi.org/10.1007/s10803-009-0840-2

Lane, A. E., Molloy, C. A., \& Bishop, S. L. (2014). Classification of children with autism spectrum disorder by sensory subtype: A case for sensory-based phenotypes. Autism Research: Official Journal of the International Society for Autism Research, 7(3), 322-333. https://doi.org/10.1002/aur.1368

Leekam, S. R., Nieto, C., Libby, S. J., Wing, L., \& Gould, J. (2007). Describing the sensory abnormalities of children and adults with autism. Journal of Autism and Developmental Disorders, 37(5), 894-910. https://doi.org/10.1007/s10803-006-0218-7

Liss, M., Saulnier, C., Fein, D., \& Kinsbourne, M. (2006). Sensory and attention abnormalities in autistic spectrum disorders. Autism: The
International Journal of Research and Practice, 10(2), 155-172. doi: https://doi.org/10.1177/1362361306062021

Maenner, M., Shaw, K., Baio, J., Washington, A., Patrick, M., \& DiRienzo, M.,... Dietz, P.M. (2020). Prevalence and characteristics of autism spectrum disorder among children aged 8 years-Autism and Developmental Disabilities Monitoring Network, 11 sites, United States, 2016. Morbidity and Mortality Weekly Report, 69(4), 1-12. https://doi.org/10.15585/mmwr.ss6904a1

Marco, E. J., Hinkley, L. B. N., Hill, S. S., \& Nagarajan, S. S. (2011) Sensory processing in autism: A review of neurophysiologic findings. Pediatric Research, 69, 48R-54R. https://doi.org/10.1203/ PDR.0b013e3182130c54

Matson, J. L., \& Shoemaker, M. (2009). Intellectual disability and its relationship to autism spectrum disorders. Research in Developmental Disabilities, 30(6), 1107-1114. https://doi.org/10.1016/j. ridd.2009.06.003

Matson, J. L., Rivet, T. T., Fodstad, J. C., Dempsey, T., \& Boisjoli, J. A. (2009). Examination of adaptive behavior differences in adults with autism spectrum disorders and intellectual disability. Research in Developmental Disabilities, 30(6), 1317-1325. https://doi.org/10.1016/j.ridd.2009.05.008

Mazurek, M. O., Vasa, R. A., Kalb, L. G., Kanne, S. M., Rosenberg, D., Keefer, A., \& Lowery, L. A. (2012). Anxiety, sensory over-responsivity, and gastrointestinal problems in children with autism spectrum disorders. Journal of Abnormal Child Psychology, 41(1), 165-176. https://doi.org/10.1007/s10802-012-9668-x

McCormick, C., Hepburn, S., Young, G. S., \& Rogers, S. J. (2016). Sensory symptoms in children with autism spectrum disorder, other developmental disorders and typical development: A longitudinal study. Autism, 20(5), 572-579. https://doi.org/10.1177/ 1362361315599755

Miller, L. J., \& Lane, S. J. (2000). Toward a consensus in termonology [sic] in sensory integration theory and practice: Part 1: Taxonomy of neurophysiological processes. Sensory Integration Special Interest Section Quarterly, 23(1), 1-4.

Miller, L. J., Anzalone, M. E., Lane, S. J., Cermak, S. A., \& Osten, E. T. (2007). Concept evolution in sensory integration: A proposed nosology for diagnosis. The American Journal of Occupational Therapy: Official Publication of the American Occupational Therapy Association, 61(2), 135-140. https://doi.org/10.5014/ ajot.61.2.135

Moher, D., Liberati, A., Tetzlaff, J., Altman, D.G. The PRISMA Group. (2009). Preferred reporting items for systematic reviews and meta-analyses: The PRISMA statement. PLoS Medicine, 6(7), e1000097. https://doi.org/10.1371/journal.pmed.1000097

Mottron, L., Dawson, M., \& Soulières, I. (2009). Enhanced perception in savant syndrome: Patterns, structure and creativity. Philosophical Transactions of the Royal Society of London. Series B, Biological Sciences, 364(1522), 1385-1391. doi: https://doi.org/ 10.1098/rstb.2008.0333

Nadon, G., Feldman, D. E., Dunn, W., \& Gisel, E. (2011). Association of sensory processing and eating problems in children with autism spectrum disorders. Autism Research and Treatment, 2011, 541926. https://doi.org/10.1155/2011/541926

O’Donnell, S., Deitz, J., Kartin, D., Nalty, T., \& Dawson, G. (2012). Sensory processing, problem behavior, adaptive behavior, and cognition in preschool children with autism spectrum disorders. American Journal of Occupational Therapy, 66(5), 586-594. https://doi.org/10.5014/ajot.2012.004168

Rogers, S. J., Hepburn, S., \& Wehner, E. (2003). Parent reports of sensory symptoms in toddlers with autism and those with other developmental disorders. Journal of Autism and Developmental Disorders, 33(6), 631-642. https://doi.org/10.1023/b:jadd.00000 06000.38991.a7

Schauder, K. B., \& Bennetto, L. (2016). Toward an interdisciplinary understanding of sensory dysfunction in autism spectrum 
disorder: An integration of the neural and symptom literatures. Frontiers in Neuroscience, 10, 268. https://doi.org/10.3389/fnins. 2016.00268

Schulz, S. E., \& Stevenson, R. A. (2019). Sensory hypersensitivity predicts repetitive behaviours in autistic and typically-developing children. Autism, 23(4), 1028-1041. https://doi.org/10.1177/ 1362361318774559

Suarez, M. A. (2012). Sensory processing in children with autism spectrum disorders and impact on functioning. Pediatric Clinics of North America, 59(1), 203-214. https://doi.org/10.1016/j.pcl. 2011.10.012

Tomchek, S. D., \& Dunn, W. (2007). Sensory processing in children with and without autism: A comparative study using the Short
Sensory Profile. American Journal of Occupational Therapy, 61(12), 190-200. https://doi.org/10.5014/ajot.61.2.190

Uljarevic, M., Lane, A., Kelly, A., \& Leekam, S. (2016). Sensory subtypes and anxiety in older children and adolescents with autism spectrum disorder. Autism Research, 9(10), 1073-1078. https:// doi.org/10.1002/aur.1602

Wolff, J. J., Dimian, A. F., Botteron, K. N., Dager, S. R., Elison, J. T., Estes, A. M., ... IBIS Network. (2019). A longitudinal study of parent-reported sensory responsiveness in toddlers at-risk for autism. Journal of Child Psychology and Psychiatry, and allied disciplines, 60(3), 314-324. doi:https://doi.org/10.1111/jcpp. 12978

Publisher's Note Springer Nature remains neutral with regard to jurisdictional claims in published maps and institutional affiliations. 